\title{
Preventing type 2 diabetes: scaling up to create a prevention system
}

E very day an estimated 280 Australians develop type 2 diabetes. ${ }^{1}$ By 2023, type 2 diabetes is predicted to become the number one specific cause of burden of disease in Australia. ${ }^{2}$ Policies and programs to support the prevention of type 2 diabetes need to be scaled up urgently if Australia hopes to limit or reduce the enormous negative impact this serious and complex condition has on individuals, families, employers, businesses and governments. An estimated 1.5 million Australians have type 2 diabetes, and this is predicted to increase to 3.3 million by $2031 .{ }^{3}$ Prediabetes, which includes impaired glucose tolerance and impaired fasting glucose, is estimated to affect 2 million Australians, putting them at high risk of developing type 2 diabetes. ${ }^{4}$

\section{"efforts to establish a sustained and effective prevention system in Australia have been patchy"}

Type 2 diabetes is a serious and progressive condition. If not identified and well managed it can lead to many complications, including macrovascular complications (heart attacks, strokes, amputations); microvascular complications (eye, kidney and nerve damage); and mental health problems (depression, anxiety and distress). Importantly, the macrovascular complications may begin early in the prediabetes stage. In Australia, diabetes accounts for one-third of all preventable hospital admissions coupled with longer than average stays. The economic cost is increasing dramatically and is estimated at $\$ 14.6$ billion per year. ${ }^{5}$

There can be no doubt that this is a serious epidemic that will have a large negative impact on health and productivity. However, despite strong evidence and many powerful tools to help prevent the future growth of type 2 diabetes, efforts to establish a sustained and effective prevention system in Australia have been patchy, project oriented and subject to frequent funding disruption due to government change and short-term thinking.

Greg Johnson BPharm, MBA

Jane E Martin $\mathrm{BA}$ (Hons), $\mathrm{MPH}^{2}$

Amy Timoshanko BAppSci(Hons), PhD

1 Diabetes Australia Canberra, ACT.

2 The Cancer Council Victoria Melbourne, VIC.

3 Diabetes Victoria Melbourne, VIC.

gjohnson@

diabetesaustralia. com.au

doi: 10.5694/mjal4.01153
The International Diabetes Federation consensus statement $^{6}$ on prevention of type 2 diabetes published in 2007 clearly identified two key target activities for prevention to be undertaken simultaneously - a high-risk population approach combined with an entire population approach. However, few countries have implemented this combined approach on a scale large enough to create a prevention system that can work effectively.

In Australia, the state of Victoria is the most advanced, with the combination of a statewide, high-risk population, diabetes prevention program (Life! program) combined with an entire population and systems approach across 12 local government areas (Healthy Together

\section{Summary}

- About 2 million Australians have prediabetes and are at high risk of developing type 2 diabetes.

- Type 2 diabetes is a fast-growing epidemic and the economic costs are estimated to be $\$ 14.6$ billion per year in Australia.

- Strong evidence from randomised controlled trials shows type 2 diabetes can be prevented in up to $58 \%$ of people at high risk, through structured lifestyle intervention.

- Good evidence and experience obtained from translational studies in Australia shows we can deliver effective community-based prevention programs.

- To be effective, a national strategy for prevention of type 2 diabetes should involve two concurrent approaches - a targeted approach aimed at those most at risk (ie, with prediabetes) combined with an environments, systems and behaviour approach for the entire population.

- Australia's current efforts in both these areas are not nationwide, not large scale and often not sustained.

Victoria), as well as the LiveLighter campaign to encourage Victorians to live healthier lifestyles.

So what works and how do we scale up to create effective prevention?

\section{High-risk population prevention}

Up to $58 \%$ of type 2 diabetes developing from the prediabetes population can be prevented through intensive, structured lifestyle interventions. ${ }^{78}$ There is strong evidence from randomised controlled trials (RCTs) around the world to support this approach. Furthermore, costeffectiveness studies and community-based evaluations conclude that these interventions are able to be implemented, and are effective and cost-effective.,10

The effect of lifestyle intervention has an impact lasting up to 20 years after the active intervention. ${ }^{7}$ The drug metformin can also prevent type 2 diabetes in individuals at high risk. ${ }^{11}$ While it is not as effective as a lifestyle modification program, metformin is an appropriate and effective intervention for some people. ${ }^{12}$ Lifestyle intervention alone is less effective in those with severe obesity, whereas bariatric surgery ${ }^{13}$ has been shown to be effective.

Translational studies including the Greater Green Triangle Diabetes Prevention Project, ${ }_{1}^{14}$ Sydney Diabetes Prevention Program (SDPP), ${ }_{1}^{15}$ and the large-scale implementation of the Victorian Life! program ${ }^{16,17}$ have built a strong case that the RCT evidence can be translated into community-based 
programs. These programs have included face-to-face group interventions and individual telephone interventions, both with 5-6 structured sessions and trained facilitators. Maintaining the fidelity of these lifestyle interventions through accreditation or certification is important.

The questionnaire-based Australian Type 2 Diabetes Risk Assessment Tool (AUSDRISK) has made screening to identify and recruit individuals at high risk feasible and effective at a community level. The Workhealth program in Victoria (no longer funded) used the AUSDRISK tool for over 500000 worker health checks, and around 23\% of workers were found to be at high risk. ${ }^{18}$ Lamentably, most were not systematically referred for any follow-up or prevention intervention. The Life! program has seen over 59000 people with prediabetes referred to lifestylebased prevention courses. This has been achieved by establishing multiple recruitment methods that include: integrated social marketing techniques using mass media and online media; effective risk messaging about the seriousness and personal relevance; workplace and community promotions; and a call-to-action response system with a telephone response line similar to Quitline.

A framework for scaling up high-risk population prevention in Australia should be based on international experience (United States Centers for Disease Control National Diabetes Prevention Program) and local implementation models (SDPP and Victorian Life! program). Importantly, a national approach should reflect a national commitment and integrate national and state or territory government funding with private health insurance funding, employer funding (for workplace-based elements) and individual contribution. This partnership of funders has been established in the US program.

A national type 2 diabetes high-risk prevention program should include six key strategies:

- Marketing risk messages with a clear call to action as well as a telephone response and support line;

- Systematically identifying high-risk individuals in community settings, online and in primary care;

- Intervention based on the most appropriate pathway for prevention;

- Intensive lifestyle programs (face-to-face groups, telephone, webinar groups, commercial programs)

- Medication (metformin)

- Surgery (for those with severe obesity)

- Building a prevention workforce;

- Continuous improvement, evaluation and innovation;

- National coordination and collaboration.

\section{Entire population approach}

Driving the development and increasing prevalence of type 2 diabetes is the increase in modifiable risk factors, particularly unhealthy diets, physical inactivity, weight gain and overweight and obesity. There is a seven times greater risk of diabetes among obese people compared with those of healthy weight, with a threefold increase in risk among overweight people. ${ }^{19}$ The modifiable risk factors for type 2 diabetes are common risk factors for cardiovascular disease, kidney disease and many cancers.

Entire population prevention action must be multi-faceted and include legislation or regulation, fiscal incentives, social marketing, health promotion and the provision of public health services. ${ }^{20}$ It should target policy, structural and environmental factors to reduce the proportion of people shifting from healthy weight to overweight to obese, and low risk to high risk. ${ }^{21}$

The United Kingdom Foresight report ${ }^{22}$ provided a clear framework for national action. The experts and evidence pointed to an environments, systems and behaviour approach that reflects the following elements:

- Food environment (production and formulation, labelling and consumption, marketing)

- Activity environment (built environment, transport)

- Societal influences (attitudes, education, cultures)

- Individual influences (behaviour, choices, families)

- Biological influences (genetics and epigenetics)

\section{National Preventative Health Taskforce report}

The evidence has also been reviewed in Australia and an excellent evidence-based framework for national action was proposed in the National Preventative Health Taskforce report. ${ }^{23}$ However, as described below, implementation by either national or state or territory governments has been scarce.

Driving change in the food supply to increase the availability and demand for healthier food products and decrease the availability and demand for unhealthy food products. There has been some work on improving food labelling to support and empower consumers to make healthier choices. Agreement has been reached around a new interpretive front-of-pack healthy star labelling system that aims to empower people to make healthier choices. Adoption of the system will be supported by a social marketing campaign, and its success will be enhanced if use is widespread. Agreement has also been reached that high-level health claims will not be able to be used on foods that are determined to be unhealthy overall. Next steps could include the development of a nutrition policy to set out strategies for improving diets. Much more needs to be done towards achieving reformulation of processed foods to reduce added sugar, salt and fat.

Reduce the exposure of children and others to the marketing and promotion of unhealthy foods. Australia relies to a large extent on a self-regulatory system; however, there is little evidence that this has significantly reduced the power and volume of marketing to which children are exposed. Increasingly, digital and social media, which are harder for parents to monitor, are being integrated into marketing campaigns. A single agreed definition of unhealthy foods that cannot be marketed 
to children has not been developed. The excessive marketing and consumption of sugar-sweetened beverages, which especially affects children and young people, and the continuing expansion of this category beyond traditional soft drinks are a particular focus of national and international public health advocacy.

Drive environmental changes throughout the community to increase levels of physical activity and reduce sedentary behaviours. There has been little policy or systematic effort to drive this, and high-level leadership and development of a national framework for active living is still needed.

Embed physical activity and healthy eating in everyday life, including workplaces, school and communities. Some jurisdictions have established a systematic approach; for example, South Australia has established the OPAL (Obesity Prevention and Lifestyle) program and Victoria the Healthy Together Victoria initiative, which target a range of settings.

Encourage people to improve physical activity and healthy eating through social marketing. Some efforts commenced at the national level with the Measure Up and Swap It, Don't Stop It campaigns, but these are no longer funded. A number of jurisdictions have rolled out the LiveLighter campaign in order to target diets and sedentary behaviour through small, sustainable changes.

Strengthen skill and support primary health care and the public health workforce to support people making healthy choices. Since this recommendation was made, in 2013 the National Health and Medical Research Council developed clinical practice guidelines ${ }^{24}$ to support the management of overweight and obesity by health professionals.

The entire population approach also requires a focus on low-income communities and cultural and linguistic diversity.

\section{Two population groups requiring special consideration}

Indigenous Australians are three times more likely than non-Indigenous Australians to have type 2 diabetes and more likely to develop complications. ${ }^{25}$ Prevention efforts needed for Indigenous Australians require urgent attention but were beyond the scope of our review.

Women who develop gestational diabetes (about 5\%-10\% of pregnancies ${ }^{26}$ ) have an increased future risk of developing type 2 diabetes, and their children also have an increased health risk. Increasing evidence for the importance of in utero factors to the risk of type 2 diabetes in adult life owing to epigenetic mechanisms ${ }^{27}$ suggests that further examination of diabetes prevention strategies specific to maternal and child health is also required.

\section{Conclusions}

For decades Australia has led the way in large-scale approaches in some key areas of prevention. A prominent example is the international leadership shown in tobacco control through the combination of social marketing, evidence-based interventions, and regulatory and policy initiatives, together with monitoring and evaluation.

It is over 10 years since the first international RCTs reported that we can prevent the development of type 2 diabetes in the high-risk population (with prediabetes). It is over 5 years since the National Preventative Health Taskforce report. Yet there has been little national action.

In 2013, Diabetes Australia called for a new national diabetes strategy with prevention as the focus. It also pointed to the need for sustained national action for prevention of type 2 diabetes through a combined approach of a national diabetes prevention program (targeting the highrisk population) concurrent with serious national, societal change to create healthy food and activity environments and support healthy choices by making them affordable and accessible.

It is encouraging that the Australian Government is proceeding with its commitment to develop a new national diabetes strategy and has formed a national advisory group and established a timeline for completion in early 2015.

Short-term pilot projects will not be enough. Small-scale programs will not be enough. Prevention of type 2 diabetes is proven, possible and powerful - but to achieve this we need to scale up our national effort and create a sustained prevention system for the next decade and beyond.

Competing interests: No relevant disclosures.

Provenance: Commissioned; externally peer reviewed. 
1 Magliano DJ, Peeters A, Vos T, et al. Projecting the burden of diabetes in Australia: what is the size of the matter? Aust NZ J Public Health 2009; 33: 540-543.

2 Australian Institute of Health and Welfare. Australia's Health 2010. Canberra: AlHW, 2010. (AlHW Cat. No. AUS 122; Australia's Health Series No. 12.) http://www.aihw.gov.au/ publication-detail/?id=6442468376 (accessed Dec 2014).

3 Vos T, Goss J, Begg S, Mann N. Projected health care costs report. Australian Burden of Disease and Injury Study. University of Queensland and Australian Institute of Health and Welfare, 2005.

4 Dunstan D, Zimmet P, Welborn T, et al; AusDiab Steering Committee. Diabesity and associated disorders in Australia 2000. The accelerating epidemic. Australian diabetes, obesity and lifestyle report 2001. Melbourne: International Diabetes Institute, 2001.

5 Lee CM, Colagiuri R, Magliano DJ, et al. The cost of diabetes in adults in Australia. Diabetes Res Clin Pract 2013; 99: 385-390.

6 Alberti KG, Zimmet P, Shaw J. International Diabetes Federation: a consensus on type 2 diabetes prevention. Diabet Med 2007; 24: 451-463.

7 Uusitupa M, Lindi V, Louheranta A, et al; Finnish Diabetes Prevention Study Group. Long-term improvement in insulin sensitivity by changing lifestyles of people with impaired glucose tolerance: 4-year results from the Finnish Diabetes Prevention Study. Diabetes 2003; 52: 2532-2538.

8 Knowler WC, Barret-Connor E, Fowler SE, et al. Reduction in the incidence of type 2 diabetes with lifestyle intervention or metformin. N Engl J Med 2002; 346: 393-403.

9 Vos T, Carter R, Barendregt J, et al; ACE-Prevention Team. Assessing Cost-Effectiveness in Prevention (ACE-Prevention): final report. Brisbane: University of Queensland; Melbourne: Deakin University, 2012. http://www.sph.uq.edu.au/docs/ BODCE/ACE-P/ACE-Prevention_final_report.pdf (accessed Dec 2014).

10 Palmer AJ, Tucker DM. Cost and clinical implications of diabetes prevention in an Australian setting: a long-term modeling analysis. Prim Care Diabetes 2012; 6: 109-121.

11 Diabetes Prevention Program Research Group. The 10-year cost-effectiveness of lifestyle intervention or metformin for diabetes prevention: an intent-to-treat analysis of the DPP/ DPPOS. Diabetes Care 2012; 35: 723-730.

12 Gillies CL, Abrams KR, Lambert PC, et al. Pharmacological and lifestyle interventions to prevent or delay type 2 diabetes in people with impaired glucose tolerance: systematic review and meta-analysis. BMJ 2007; 334: 299.

13 Carlsson LM, Peltonen M, Ahlin S, et al. Bariatric surgery and prevention of type 2 diabetes in Swedish obese subjects. $N$ Engl J Med 2012; 367: 695-704.

14 Laatikainen T, Dunbar JA, Chapman A, et al. Prevention of type 2 diabetes by lifestyle intervention in an Australian primary health care setting: Greater Green Triangle (GGT) Diabetes Prevention Project. BMC Public Health 2007; 7: 249.

15 Colagiuri S, Vita P, Cardona-Morrell M, et al. The Sydney Diabetes Prevention Program: a community-based translational study. BMC Public Health 2010; 10: 328.
16 Reddy P, Rankins D, Timoshanko A, Dunbar JA. Life! in Australia: translating prevention research into a largescale intervention. Br J Diabetes Vasc Dis 2011; 11: 193-197. doi: 10.1177/1474651411410724.

17 Vita P, Reddy P, Timoshanko A, et al. What do we know about recruitment and retention in diabetes prevention programs? An Australian perspective. In: Schwarz P, Reddy P, editors. Prevention of diabetes. Oxford: John Wiley \& Sons, 2013: Ch. 4.

18 WorkHealth, WorkSafe Victoria. WorkHealth checks. Selected findings. October 2012. http://www.vwa.vic.gov.au/_data/ assets/pdf_file/0006/120849/WorkHealth-checks-500Kresults-fact-sheet.pdf (accessed Aug 2014).

19 Abdullah A, Peeters A, de Courten M, Stoelwinder J. The magnitude of association between overweight and obesity and the risk of diabetes: a meta-analysis of prospective cohort studies. Diabetes Res Clin Pract 2010; 89: 309-319.

20 Australian National Preventive Health Agency. State of preventive health 2013. Report to the Australian Government Minister for Health. Canberra: ANPHA, 2013. http://www. anpha.gov.au/internet/anpha/publishing.nsf/Content/ state-of-prev-health-2013 (accessed Dec 2014).

21 Pincock S. Boyd Swinburn: combating obesity at the community level. Lancet 2011; 378: 761.

22 Butland S, Jebb S, Kopelman P, et al; UK Government Foresight Programme. Tackling obesities: future choices - project report. 2nd ed. London: Government Office for Science, 2007. https://www.gov.uk/government/uploads/ system/uploads/attachment_data/file/287937/07-1184Xtackling-obesities-future-choices-report.pdf (accessed Dec 2014).

23 Australian Government Preventative Health Taskforce. Australia: the healthiest country by 2020. National Preventative Health Strategy - Overview. Canberra: Commonwealth of Australia, 2009. http://www. preventativehealth.org.au/internet/preventativehealth/ publishing.nsf/Content/nphs-overview (accessed Dec 2014).

24 National Health and Medical Research Council. Clinical practice guidelines for the management of overweight and obesity in adults, adolescents and children in Australia (2013). http://www.nhmrc.gov.au/guidelines/publications/n57 (accessed Aug 2014).

25 Shaw J, Tanamas S. Diabetes: the silent pandemic and its impact on Australia. Melbourne: Baker IDI Heart and Diabetes Institute, 2012. http://www.diabetesaustralia.com.au/ Documents/DA/What's\%20New/12.03.14\%20Diabetes\%20 management\%20booklet\%20FINAL.pdf (accessed Dec 2014).

26 Australian Institute of Health and Welfare. Diabetes in pregnancy: its impact on Australian women and their babies. Canberra: AlHW, 2010. (AlHW Cat. No. CVD 42.) http://www. aihw.gov.au/publication-detail/?id=6442472448\&tab=2 (accessed Dec 2014).

27 Gluckman PD, Hanson M, Zimmet P, Forrester T. Losing the war against obesity: the need for a developmental perspective. Sci Transl Med 2011; 3: 93cml9. 